\title{
Multifactorial analysis of the surgical outcomes of giant congenital melanocytic nevi: Single versus serial tissue expansion
}

\author{
Min Ji Kim, Dong Hwan Lee, Dong Ha Park \\ Department of Plastic and Reconstructive Surgery, Ajou University School of Medicine, Suwon, Korea
}

Background Giant congenital melanocytic nevus (GCMN) is a rare disease, for which complete surgical resection is recommended. However, the size of the lesions presents problems for the management of the condition. The most popular approach is to use a tissue expander; however, single-stage expansion in reconstructive surgery for GCMN cannot always address the entire defect. Few reports have compared tissue expansion techniques. The present study compared single and serial expansion to analyze the risk factors for complications and the surgical outcomes of the two techniques.

Methods We retrospectively reviewed the medical charts of patients who underwent tissue expander reconstruction between March 2011 and July 2019. Serial expansion was indicated in cases of anatomically obvious defects after the first expansion, limited skin expansion with two more expander insertions, or capsular contracture after removal of the first expander.

Results Fifty-five patients (88 cases) were analyzed, of whom 31 underwent serial expansion. The number of expanders inserted was higher in the serial-expansion group $(P<0.001)$. The back and lower extremities were the most common locations for single and serial expansion, respectively $(P=0.043)$. Multivariate analysis showed that sex (odds ratio $[O R], 0.257$; $P=0.015)$, expander size $(O R, 1.016 ; P=0.015)$, and inflation volume $(O R, 0.987 ; P=0.015)$ were risk factors for complications.

Conclusions Serial expansion is a good option for GCMN management. We demonstrated that large-sized expanders and large inflation volumes can lead to complications, and therefore require risk-reducing strategies. Nonetheless, serial expansion with proper management is appropriate for certain patients and can provide aesthetically satisfactory outcomes.

Keywords Nevus, pigmented / Skin neoplasms / Tissue expansion / Tissue expansion devices / Surgical flaps
Correspondence: Dong Ha Park Department of Plastic and Reconstructive Surgery, Ajou University Medical Center, Ajou University School of Medicine, 164 World cup-ro, Yeongtong-gu, Suwon 16499, Korea Tel: +82-31-219-5614 Fax: +82-31-219-5610 E-mail: growhand@hanmail.net

Received: July 22, 2020 • Revised: October 22, 2020 • Accepted: November 3, 2020

pISSN: 2234-6163 • elSSN: 2234-6171 • https://doi.org/10.5999/aps.2020.01494 • Arch Plast Surg 2020;47:551-558

\section{INTRODUCTION}

Giant congenital melanocytic nevus (GCMN) is characterized by the innate proliferation of melanocytes in the epidermis or dermis, resulting in the development of pigmented birthmarks. It is a rare disease, occurring in about 1 in 20,000 newborns, and complete surgical resection is recommended because it has a considerable potential for malignant transformation, with possi-

Copyright $(\odot) 2020$ The Korean Society of Plastic and Reconstructive Surgeons

This is an Open Access article distributed under the terms of the Creative Commons Attribution Non-Commercial License (https://creativecommons.org/

licenses/by-nc/4.0/) which permits unrestricted non-commercial use, distribution, and reproduction in any medium, provided the original work is properly cited.

www.e-aps.org 
bly fatal outcomes $[1,2]$. GCMN usually involves more than one body segment, and there can be psychological consequences for pediatric patients and their parents. Therefore, surgical treatment for GCMN frequently involves reconstructive surgery after resection [3].

Unlike small- or medium-sized nevi, GCMN always exhibits uncontrolled large dimensions, which presents challenges for surgical management. A tissue expander is the most popular approach for surgical treatment, as this technique can maintain skin texture with low donor site morbidity $[4,5]$. Once the tissue expander is inserted adjacent to the lesion, the injection of volume causes expansion of the full thickness of the soft tissue [6]. A second operation is then required to remove the expander and create a local advancement flap or a rotational flap. However, excessive skin expansion can lead to complications such as rupture, infection, or skin necrosis, which can be especially severe in pediatric patients. Therefore, single-stage expansion for reconstruction surgery cannot always address the entire defect associated with GCMN.

Serial expansion aims to overcome the limitations of expansion in terms of the available surrounding tissue during the early stages of tissue expansion [7]. Recently, serial expansion has been suggested as a way to increase the expansion rate and has been proposed as a surgical option [8]. Although several reports have demonstrated the safety and efficacy of tissue expansion, there are concerns about infection, device exposure, and flap tissue loss. Physicians tend to hesitate to select serial expansion because of these potential complications, which make it difficult to decide whether to perform single or serial tissue expansion.

Since pediatric surgery receives relatively little research attention, only a few reports have been published on various techniques of tissue expansion in pediatric patients. We support the necessity of serial expansion and its utility for large soft-tissue defects; however, limited studies have provided a comprehensive analysis of the procedure. The present study, therefore, analyzed the features of pediatric patients undergoing expander insertion for GCMN. By comparing single and serial expansion techniques, we investigated the risk factors associated with complications and the surgical outcomes. The identification of relevant risk factors could help to establish preoperative strategies for insertion.

\section{METHODS}

We retrospectively recruited patients who underwent tissue expander reconstruction following GCMN excision between March 2011 and July 2019. The exclusion criteria were tissue expander insertion for trauma or scar reconstruction. Data were collected by a review of patients' medical charts.

We analyzed patients' demographic characteristics (age, sex, height, weight, and body mass index [BMI]), characteristics of the tissue expander (manufacturer, model name, capacity, and shape), and characteristics of inflation (type of expansion, expander insertion site, presence of an external port, volume of the inflated expander, and follow-up days). The expander insertion sites were categorized into five locations: head, lower extremity, upper extremity, back, or trunk.

\section{Operative details}

All operations were performed by a single plastic surgeon (DHP) under general anesthesia. Ampicillin and sulbactam were administered as perioperative antibiotics except in patients with known allergic reactions. The nature of the skin incision depended on the expander insertion site. On the back, the incision was made transversely above the highest level of the iliac crest. At all other sites, the incision was made parallel to the border of the giant nevus. The expander was inserted to the level of the deep fascia after meticulous dissection. In the scalp, the expander was inserted in the subgaleal plane. A drain was placed in the pocket into which the expander was inserted and was removed when the drainage volume had decreased to below $10 \mathrm{~mL}$ over 24 hours. The elevated flap was closed with interrupted 3-0 or 4-0 absorbable sutures in the deep fascia and interrupted 4-0 or 5-0 nylon skin sutures. A port was placed in the pocket for saline injection if there was sufficient space; otherwise, it was placed outside the skin through the tube. Initial inflation was performed immediately postoperatively to maintain adequate capillary refill time and tension.

\section{Expander inflation protocol}

After insertion of the tissue expander, patients visited the outpatient department to fill the expander every week. We aimed to fill the expander to the rated capacity where possible and performed additional inflation if the skin flap had sufficient biomechanical capacity. The amount of inflation was categorized as under-inflation (filled to more than $10 \%$ below the rated capacity), over-inflation (filled more than $10 \%$ above the rated capacity), or inflation to capacity. In patients with systemic conditions or an unstable skin flap, the expander was underinflated. The second-stage operation to remove the expander and to perform nevus excision was carried out approximately 3 months (mean: $80.74 \pm 28.20$ days) after the first operation.

\section{Comparison of single and serial expansion techniques}

Serial expansion was carried out in cases where the congenital giant nevus could not be removed with a single tissue expansion 
procedure. Once the nevus was measured and compared with the surrounding normal tissue, if one expander insertion was determined to be insufficient to cover the defect, we performed two expander insertions in a single-stage operation. If it was not possible to insert two or more expanders at the target lesion, serial expansion was performed. In some cases, when two more expanders were inserted at a single site, defects were uncovered after removal of the expander. Serial expansion was also performed in those cases. Finally, changes in the composition of the surrounding tissue after removal of the expander sometimes resulted in formation of a fibrous capsule, meaning that the local flap could not be created as planned $[9,10]$. In this situation, serial expansion was also performed (Figs. 1,2).

\section{Statistical analysis}

Statistical analyses were performed using SPSS for Windows version 18.0 (SPSS Inc., Chicago, IL, USA). Data are presented as mean \pm two standard deviations. Statistical significance was accepted at $\mathrm{P}<0.05$. Normally distributed continuous variables were compared using the Student t-test; non-normally distributed continuous variables were compared using the MannWhitney U-test. The Pearson chi-square test was performed to evaluate qualitative data. Factors that predicted expander-related complications were identified through univariate analysis. Vari- ables with a P-value of under 0.05 were included in the multivariate analysis. Backward stepwise logistic regression analysis was then performed to identify risk factors for expander-related complications.

\section{RESULTS}

In total, 55 patients were included in this retrospective study. Multiple separated nevus lesions in a single patient were counted individually as separate cases. Thus, 88 cases were analyzed. Of the total study population, 17 patients underwent dual-expander insertion into a single nevus lesion in a single-stage operation, while 14 underwent multiple expander insertion into a single nevus lesion in multiple operations. Cases that underwent dual-expander or multiple-stage operations were categorized into the serial-expansion group.

The patients' mean age was 6.59 years and the female-to-male ratio was 1.38. The most common pathologic type of nevus was compound nevus (59.09\%), followed by intradermal nevus $(6.82 \%)$. The most common location of the nevi was the back (38.77\%), followed by the head (29.55\%) and lower extremity (25.00\%). The mean follow-up period after expander removal was 23.74 months (Table 1 ).

A comparison of the clinical and operative details of cases be-

Fig. 1. The single-expansion technique

Photographs of giant congenital melanocytic nevus treated surgically using the single-expansion technique. (A) Preoperative. (B) Full expansion. (C) Postoperative.
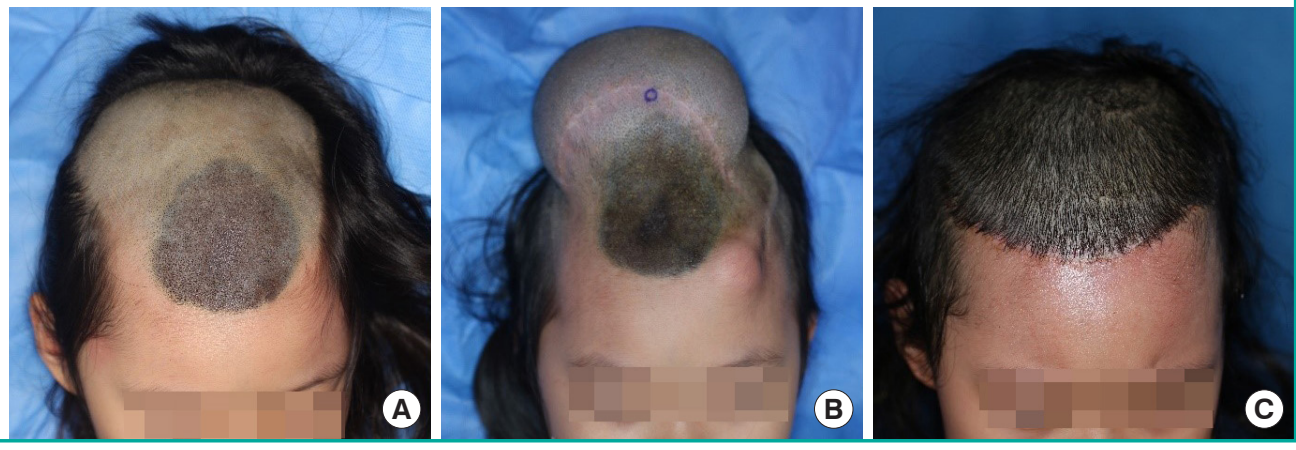

Fig. 2. The serial-expansion technique

Photographs of giant congenital melanocytic nevus treated surgically using the serial-expansion technique. (A) Preoperative. (B) Full expansion of the first tissue expander. (C) Postoperative of the first tissue expander removal. (D) Final postoperative.
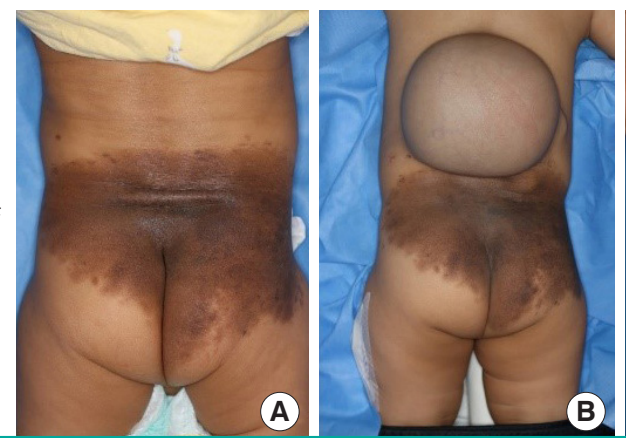

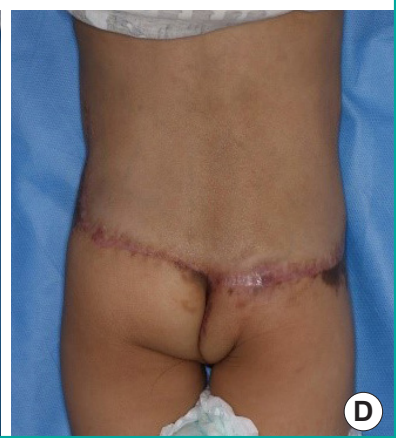


Table 1. Demographic characteristics of the study population

\begin{tabular}{|lc|}
\hline Variable & Value \\
\hline No. of subjects & 88 \\
Age (yr) & $6.59 \pm 7.76$ \\
Sex & \\
Female & $51(58.0)$ \\
Male & $37(42.0)$ \\
Body mass index (kg/m²) & $17.51 \pm 3.07$ \\
Height (cm) & $111.00 \pm 30.82$ \\
Weight (kg) & $24.03 \pm 17.67$ \\
Type of nevus & \\
Compound nevus & $52(59.1)$ \\
Intradermal nevus & $27(6.8)$ \\
Nevus sebaceous & $6(30.8)$ \\
Blue nevus & $1(1.1)$ \\
Lentiginous compound nevus & $2(2.3)$ \\
Lesion site & \\
Head & $26(29.6)$ \\
Lower extremity & $22(25.0)$ \\
Upper extremity & $3(3.4)$ \\
Back & $35(38.8)$ \\
Trunk & $2(2.3)$ \\
Manufacturer & \\
Mentor & $74(84.1)$ \\
Sebbin & $14(15.9)$ \\
Type of expander & $79(89.8)$ \\
Rectangular & $9(10.2)$ \\
Elliptical or crescent & $23.74 \pm 28.20$ \\
Follow-up period (mon) & \\
\hline Values are presented as mean \pm two standard deviations or number (\%). \\
\hline
\end{tabular}

tween the single- and serial-expansion groups is presented in Table 2. The number of expanders and the site of expansion showed statistically significant differences between these two groups. The serial-expansion groups had more expanders than the single-expansion group (single, 1.14; serial, 3.26; $\mathrm{P}<0.001$ ). Expander size and final inflation volume were larger in the serialexpansion group, although these differences were not statistically significant. The amount of expansion required to over- or under-inflate the expander depended on the perfusion status of the skin flap and was not significantly different between the two groups. There was a higher proportion of cases who received over-inflation of the expander in the single-expansion group than in the serial-expansion group. The most common expansion site, corresponding to the location where the nevus was first noted, was the back in the single-expansion group and the lower extremity in the serial-expansion group (Table 2, Fig. 3).

A comparison of the complications that were reported in each group is shown in Table 3. Requirements for revisional operations such as debridement, incision and drainage, hematoma evacuation, or explantation were also noted. The rates of infection and revisional operation were significantly higher in the serial-expansion group than in the single-expansion group (infec-
Table 2. Statistical comparison of expansion details between single and serial expansion

\begin{tabular}{|c|c|c|c|}
\hline Variable & $\begin{array}{l}\text { Single } \\
\text { expansion } \\
(n=64)\end{array}$ & $\begin{array}{c}\text { Serial } \\
\text { expansion } \\
(n=31)\end{array}$ & P-value \\
\hline Expander size (mL) & $268.75 \pm 169.41$ & $323.22 \pm 176.75$ & 0.151 \\
\hline No. of expanders & $1.14 \pm 0.63$ & $3.26 \pm 1.99$ & $<0.001^{\text {a) }}$ \\
\hline Inflation volume (mL) & $283.61 \pm 184.62$ & $324.00 \pm 186.38$ & 0.322 \\
\hline Amount of expansion & & & 0.341 \\
\hline Over-expansion & 39 (76.5) & $16(61.5)$ & \\
\hline Under-expansion & $12(23.5)$ & $10(38.5)$ & \\
\hline No. of inflations & $6.77 \pm 2.33$ & $7.70 \pm 2.57$ & 0.077 \\
\hline Inflation period (day) & $79.51 \pm 26.88$ & $85.06 \pm 33.95$ & 0.390 \\
\hline Site of expansion & & & $0.043^{\mathrm{a})}$ \\
\hline Head & 20 (31.3) & $6(19.4)$ & \\
\hline Lower extremity & $13(20.3)$ & $15(48.4)$ & \\
\hline Upper extremity & $4(6.3)$ & 0 & \\
\hline Back & $25(39.1)$ & 10 (32.3) & \\
\hline Trunk & $2(3.1)$ & 0 & \\
\hline
\end{tabular}

tion, $\mathrm{P}=0.020$; revision surgery, $\mathrm{P}=0.011$ ) (Table 3 ). The incidence of other complications was not significantly different between the two groups.

Univariate analysis identified several clinical variables associated with the development of expander-related complications. Specifically, sex, age, BMI, nevus characteristics, surgical details of expansion (type, size, location), the inflation protocol, and the inflation period were found to be associated with complications. Multivariate logistic regression analysis of these variables showed that sex (odds ratio [OR], 0.257; 95\% confidence interval $[\mathrm{CI}], 0.086-0.769 ; \mathrm{P}=0.015)$, expander size ( $\mathrm{OR}, 1.016$; 95\% CI, 1.007-1.024; $\mathrm{P}=0.015$ ), and inflation volume ( $\mathrm{OR}$, 0.987; 95\% CI, 0.979-0.995; $\mathrm{P}=0.002$ ) to be significant factors influencing the development of complications following treatment for GCMN using expander (Table 4). The type of expansion (single or serial) did not affect the incidence of expanderrelated complications. However, large expander insertion size and large inflation volume were found to increase the risk of complications.

\section{Case presentation}

\section{A case of GCMN treated surgically using the single-expansion} technique

A 57-month-old girl presented with a giant nevus on the frontal area of the head, measuring approximately $50 \mathrm{~cm}^{2}$. A 400-mL tissue expander (Mentor, Irvine, CA, USA) with a smooth rectangular shape was inserted into the scalp adjacent to the nevus. After injecting $405 \mathrm{~mL}$ of saline without any complications, the entire nevus was excised, including the expanded skin, 98 days 


\section{Fig. 3. The serial expansion in lower extremity}

Photographs of cases who underwent serial expansion for anatomically compromised congenital giant nevus. (A) Preoperative. (B) Full expansion of the first tissue expander. (C) Two years after the first expansion. (D) Postoperative of the second tissue expander removal.
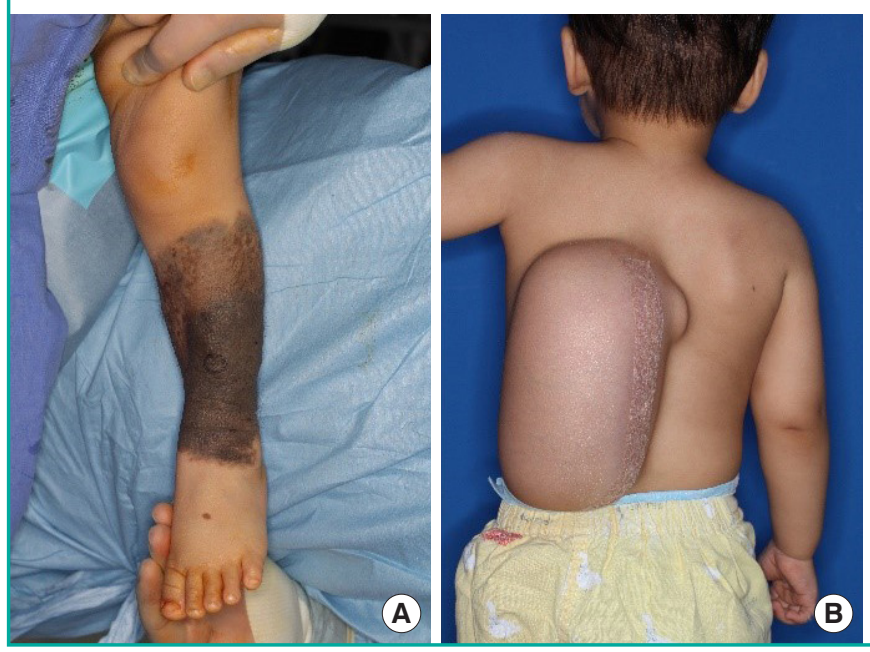

Table 3. Statistical comparison of complications between single and serial expansion

\begin{tabular}{|lccc|}
\hline Variable & $\begin{array}{c}\text { Single } \\
\text { expansion } \\
(\mathbf{n}=\mathbf{6 4})\end{array}$ & $\begin{array}{c}\text { Serial } \\
\text { expansion } \\
(\mathbf{n}=31)\end{array}$ & P-value \\
\hline Explantation & $5(7.8)$ & $6(3.6)$ & 0.101 \\
Port exposure & $4(6.3)$ & $2(6.5)$ & 0.970 \\
Skin necrosis & $3(4.7)$ & $1(3.2)$ & 0.743 \\
Hematoma/seroma & $9(14.1)$ & $3(9.7)$ & 0.551 \\
Rupture & $2(3.1)$ & $1(3.2)$ & 0.979 \\
Infection & $4(6.3)$ & $7(22.6)$ & $0.020^{\text {a) }}$ \\
Revision operation & $14(20.3)$ & $14(45.2)$ & $0.011^{\text {a) }}$ \\
\hline
\end{tabular}

Values are presented as number (\%). When a patient experienced multiple complications, the complications were counted individually.

a) Statistically significant.

later. Satisfactory results were seen at a 1-year postoperative follow-up (Fig. 1).

\section{A case of GCMN treated surgically using the serial-expansion technique}

A 6-month-old boy was admitted for a giant nevus spreading across both sides of the hips and lower back, measuring approximately $300 \mathrm{~cm}^{2}$. A 400-mL tissue expander (Mentor) with a smooth rectangular shape was inserted into the back, adjacent to the nevus. Full expansion of the first tissue expander was achieved by filling it with $490 \mathrm{~mL}$ of saline over 56 days. No complications occurred, the nevus was partially excised, and the defect was covered using the expanded skin flap. Two more serial expander insertions were performed. The second expander was filled with $500 \mathrm{~mL}$ of saline for 70 days, and the third was filled with $450 \mathrm{~mL}$ for 73 days. No complications occurred (Fig. 2).
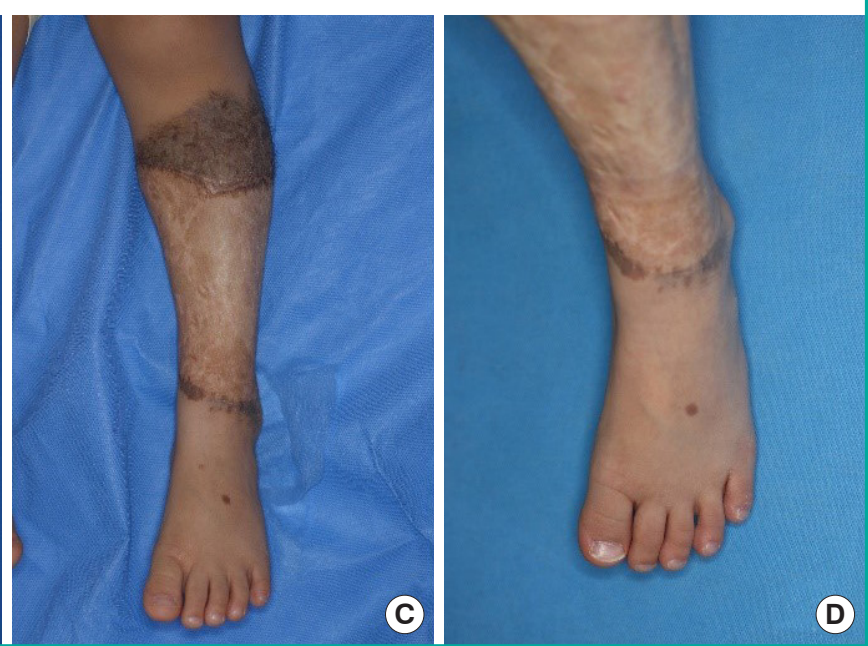

Table 4. Results of multifactorial risk analysis of expanderrelated complications

\begin{tabular}{|lcc|}
\hline Variable & OR $(95 \% \mathrm{CI})$ & P-value \\
\hline Sex & $0.257(0.086-0.769)$ & $0.015^{\mathrm{a})}$ \\
Age & $1.000(1.000-1.000)$ & 0.477 \\
BMl & $1.008(0.799-1.271)$ & 0.946 \\
Nevus type & - & 0.998 \\
Expander site & $0.689(0.022-72.894)$ & 0.890 \\
Single/serial expander & $0.851(0.158-4.579)$ & 0.851 \\
Expander type & $5.522(0.802-38.005)$ & 0.083 \\
Expander size & $1.016(1.007-1.024)$ & $<0.001^{\mathrm{a})}$ \\
Inflation volume & $0.987(0.979-0.995)$ & $0.002^{\mathrm{a})}$ \\
Over- \& under-inflation & $1.273(0.175-9.286)$ & 0.673 \\
No. of expanders & $1.292(0.728-2.294)$ & 0.381 \\
No. of inflations & $0.937(0.621-1.412)$ & 0.754 \\
Inflation period & $1.017(0.986-1.048)$ & 0.289 \\
\hline OR. odds ratio; Cl, confidence interval; BMl, body mass index. & \\
a)Statistically significant. & & \\
\hline
\end{tabular}

\section{A patient who underwent serial expansion for anatomically} compromised congenital giant nevus

A 15-month-old boy presented with a giant nevus on the lower left leg, measuring $230 \mathrm{~cm}^{2}$. As the baby was very young, he did not have sufficient expandable surrounding tissue; therefore, skin expansion was performed on his back. A 400-mL tissue expander (Mentor) with a smooth rectangular shape was inserted along the midline, with the incision on the right side. Full expansion of the first tissue expander was achieved by filling it with $600 \mathrm{~mL}$ of saline without any complications. A full-thickness skin graft was performed using the expanded skin 110 days after expansion. At 44 months of age (2 years after the first expansion), a smooth, rectangular-shaped 550-mL tissue expander 


\section{Fig. 4. The serial expansion in scalp}

Photographs of a representative case of serial expansion treatment for giant congenital melanocytic nevus. (A) Preoperative. (B) Full expansion of the first tissue expander. (C) Full expansion of the second tissue expander. (d) Postoperative.
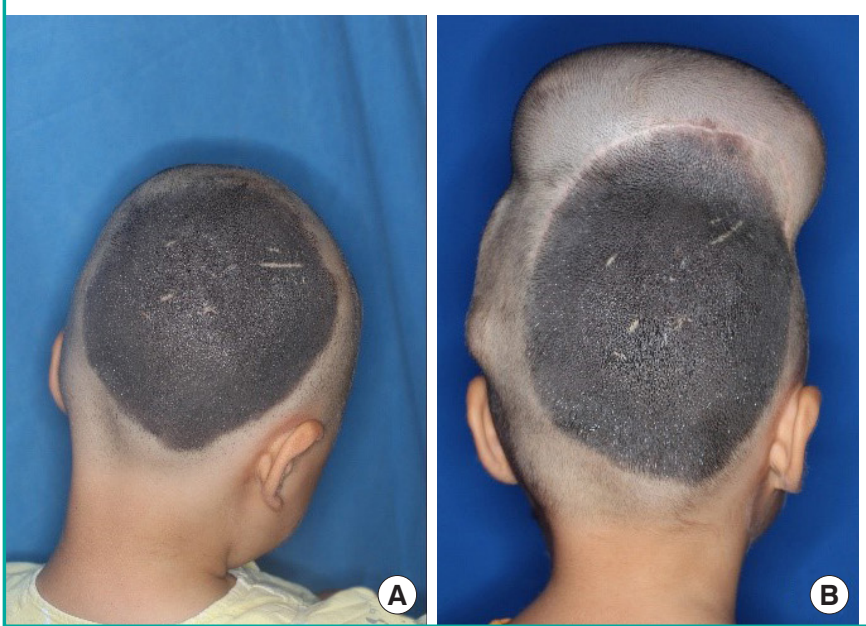

(Mentor) was inserted into the middle of the back, with the incision performed at the previous surgical scar site. A full-thickness skin graft was performed using the expanded skin from the back after filling with $600 \mathrm{~mL}$ of saline without any complications. At a follow-up visit 3 years after the initial visit, it was found that the nevus had been totally removed through twostage serial skin expansion (Fig. 3).

\section{A representative case of serial expansion treatment for GCMN}

A 59-month-old boy was admitted for a $150-\mathrm{cm}^{2}$ nevus on the occipital area of the head. In the first operation, a 550-mL tissue expander (Mentor) with a smooth rectangular shape was inserted into the vertex and parietal area adjacent to the nevus. Full expansion of the first tissue expander was achieved by filling it with $555 \mathrm{~mL}$ of saline for 105 days without any complications. The nevus was then partially removed, and the defect was covered using the expanded skin. The second-stage operation was performed 8 months after the first operation. The same expander was inserted in the same site along the previous surgical scar. Full expansion of the second tissue expander was achieved by filling it with $535 \mathrm{~mL}$ of saline for 112 days without any complications. After this, the nevus was totally removed. The patient was discharged 5 days after the operation without any further complications. Satisfactory results were seen at a 1-year postoperative follow-up (Fig. 4).

\section{DISCUSSION}

Surgical resection is recommended for the treatment of GCMN in order to prevent malignant transformation [11]. Given the psychological impacts of surgical resection, reconstructive treat-

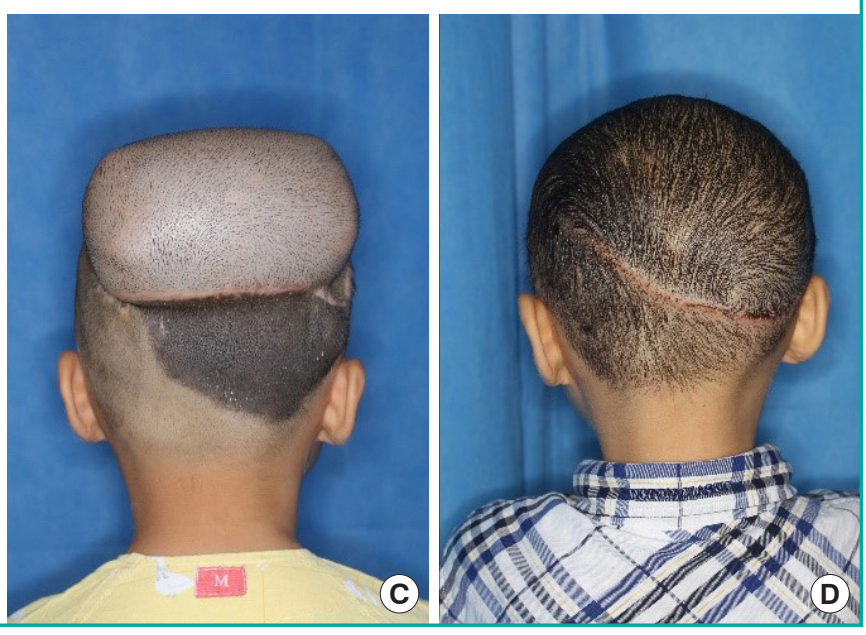

ment might be appropriate for pediatric patients [12]. However, due to the limited availability of surrounding skin with appropriate tension, choosing an appropriate reconstructive option can be challenging. Tissue expansion is a popular and widely accepted treatment option [13] and the benefits of early tissue expansion have been reported in many articles [12,14]. Since few studies have investigated the clinical applications of tissue expansion, we aimed to address this gap in the knowledge by evaluating the characteristics of different tissue expansion techniques, including the number of expanders required, how many stages of operation were needed, and the degree of inflation achieved. Because of the rarity of GCMN, gathering clinical information is difficult, even in tertiary hospitals. Here, we evaluated a large pediatric cohort and analyzed patients' clinical characteristics. Our findings regarding the risk factors for expansionrelated complications and the statistical comparison between single and serial expansion based on 10 years of clinical experience will be informative for physicians.

Serial expansion is an advanced method of tissue expansion. There are many factors which may lead to the choice of serial expansion over single expansion; of these, obtaining sufficient expanded skin is the primary reason [15]. In a series of sequential procedures, the success of the operation depends on the elasticity of the surrounding tissue (Fig. 4). Mechanical creep and the associated stress relaxation (biological creep) increase the potential for tissue expansion [16]. In the present study, we demonstrate that the insertion of multiple tissue expanders resulted in significantly different characteristics compared with the serial insertion of single tissue expanders. However, large expanders and high inflation volumes do not always necessitate serial expansion. For huge nevi (i.e., lesions over $20 \mathrm{~cm}$ in diam- 
eter), the insertion of multiple tissue expanders does not always result in a satisfactory amount of tissue, and second-stage expansion is often required at the same site. Some reports have stated that using more expanders could increase the expansion rate; however, obtaining sufficient flexibility of the tissue still required another operation, even when multiple expanders were inserted [8]. Thus, it must be accepted that serial expansion is unavoidable in some patients.

Anatomical factors are also important in the choice of the tissue expansion technique. We demonstrated that giant nevi located in the head or back could be treated satisfactorily through a single-stage operation; however, most nevi occurring in the lower extremities required serial expansion. The choice of the tissue expansion technique depends not only on the relative size and location of the nevi, but also on the treatment goal (i.e., how noticeable the nevus is), especially in pediatric patients. Many articles have reported high rates of complications associated with tissue expansion in the extremities $[17,18]$, meaning that longer inflation periods and carefully designed advancement flaps are required in these cases [19]. Due to the limited dissection area available for placement of the expander, the possibility of nerve entrapment must be considered; furthermore, skin perfusion pressure can affect cutaneous capillary refill, and thus must be accounted for $[20,21]$. We suggest that proper preoperative planning for patients with unfavorable anatomical characteristics could increase the success of reconstruction using tissue expanders.

Complications are an important concern in relation to tissue expansion in pediatric patients, especially in the context of serial expansion for GCMN. Interestingly, the present study demonstrated that the choice of the single- or serial-expansion technique was not associated with a difference in the risk of expander-related complications. Even in anatomically challenging areas such as the extremities, we found no significant differences in complications between single and serial expansion. It is generally believed that rectangular-shaped expanders could enable faster expansion [22]; however, we did not observe an increased risk of complications in the present study. Multifactorial analysis demonstrated that implantation of a larger expander and a high inflation volume were associated with a significantly higher rate of complications after expander insertion. Some complications such as infection or seroma following a foreign body reaction can be managed through conservative treatment; however, potentially fatal complications such as infection often require revisional surgery to relieve systemic problems. A significant difference according to sex was also found, but this seems to have been due to differences in behavioral patterns, rather than histologic differences according to sex. Furthermore, the psychologi- cal effects of this treatment have potentially fatal outcomes. One patient attempted suicide following second-stage expansion. This patient presented with a complex facial nevus and, having suffered from depression for years, ultimately wanted to remove the nevus. Serial expansion required a long treatment period, which the patient and parents endured. During this period, the patient could not accept the morphological changes, which contributed to the suicide attempt. Finally, explantation was performed, meaning that the ultimate treatment goal could not be met. The decision to use tissue expanders must be made very carefully in adolescents or patients with weak psychosocial support, and psychiatric counseling should be considered.

Based on our clinical experience, we believe that clinicians should not hesitate to choose serial expansion over single expansion in patients with a high risk of complications. It is true that particular anatomical conditions and the environment of the lesion may influence the decision, but successful tissue expansion should be achieved using the serial technique if the patient's presentation is appropriate. This technique is therefore a safe and easy approach for the treatment of GCMN when the factors discussed here are considered in clinical decision-making.

The treatment of GCMN using tissue expanders can be successfully achieved using the serial expansion technique. Lesions that are anatomically difficult or have a wide anticipated expansion area are indicated for serial expansion. We demonstrated that the use of this technique did not increase the risk of complications compared with single expansion. However, the use of a large expander and a high inflation volume can lead to the development of complications, and risk-reducing strategies should be considered in order to establish an appropriate treatment plan. Despite the risk of complications, proper management of GCMN through serial expansion can result in aesthetically satisfactory surgical outcomes for pediatric patients with appropriate indications.

\section{NOTES}

\section{Conflict of interest}

No potential conflict of interest relevant to this article was reported.

\section{Ethical approval}

The study was approved by the Institutional Review Board of Ajou University Medical Center (IRB No. MED-MDB-20-109) and performed in accordance with the principles of the Declaration of Helsinki. Written informed consents were obtained. 


\section{Patient consent}

The patient's parents provided written informed consent for the publication and the use of the patient's images.

\section{Author contribution}

Conceptualization: DH Park. Data curation: DH Lee. Formal analysis: MJ Kim. Project administration: MJ Kim, DH Park. Visualization: MJ Kim. Writing - original draft: MJ Kim. Writing - review \& editing: DH Lee.

\section{ORCID}

Min Ji Kim

Dong Hwan Lee

https://orcid.org/0000-0002-0723-4382

Dong Ha Park https://orcid.org/0000-0002-5436-7911 https://orcid.org/0000-0002-8024-5846

\section{REFERENCES}

1. Gosain AK, Santoro TD, Larson DL, et al. Giant congenital nevi: a 20-year experience and an algorithm for their management. Plast Reconstr Surg 2001;108:622-36.

2. Castilla EE, da Graca Dutra M, Orioli-Parreiras IM. Epidemiology of congenital pigmented naevi: I. incidence rates and relative frequencies. Br J Dermatol 1981;104:307-15.

3. Price HN, Schaffer JV. Congenital melanocytic nevi-when to worry and how to treat: facts and controversies. Clin Dermatol 2010;28:293-302.

4. Argenta LC, Marks MW, Pasyk KA. Advances in tissue expansion. Clin Plast Surg 1985;12:159-71.

5. Vander Kolk CA, McCann JJ, Knight KR, et al. Some further characteristics of expanded tissue. Clin Plast Surg 1987; 14:447-53.

6. Takei T, Mills I, Arai K, et al. Molecular basis for tissue expansion: clinical implications for the surgeon. Plast Reconstr Surg 1998;102:247-58.

7. Hudson DA, Lazarus D, Silfen R. The use of serial tissue expansion in pediatric plastic surgery. Ann Plast Surg 2000;45: 589-93.

8. Lee MK, Park SO, Choi TH. Serial tissue expansion at the same site in pediatric patients: is the subsequent expansion faster? Arch Plast Surg 2017;44:523-9.

9. Johnson TM, Lowe L, Brown MD, et al. Histology and physiology of tissue expansion. J Dermatol Surg Oncol
1993;19:1074-8.

10. Agrawal K, Agrawal S. Tissue regeneration during tissue expansion and choosing an expander. Indian J Plast Surg 2012; 45:7-15.

11. Gonzalez Ruiz Y, Lopez Gutierrez JC. Multiple tissue expansion for giant congenital melanocytic nevus. Ann Plast Surg 2017;79:e37-e40.

12. Zaal LH, van der Horst CM. Results of the early use of tissue expansion for giant congenital melanocytic naevi on the scalp and face. J Plast Reconstr Aesthet Surg 2009;62:21620.

13. Manders EK, Schenden MJ, Furrey JA, et al. Soft-tissue expansion: concepts and complications. Plast Reconstr Surg 1984;74:493-507.

14. Bauer BS, Margulis A. The expanded transposition flap: shifting paradigms based on experience gained from two decades of pediatric tissue expansion. Plast Reconstr Surg 2004;114:98-106.

15. Tepole AB, Ploch CJ, Wong J, et al. Growing skin: a computational model for skin expansion in reconstructive surgery. J Mech Phys Solids 2011;59:2177-90.

16. Mostafapour SP, Murakami CS. Tissue expansion and serial excision in scar revision. Facial Plast Surg 2001; 17:245-52.

17. LoGiudice J, Gosain AK. Pediatric tissue expansion: indications and complications. Plast Surg Nurs 2004;24:20-6.

18. Austad ED, Pasyk KA, McClatchey KD, et al. Histomorphologic evaluation of guinea pig skin and soft tissue after controlled tissue expansion. Plast Reconstr Surg 1982;70:70410.

19. Bauer BS, Vicari FA, Richard ME. The role of tissue expansion in pediatric plastic surgery. Clin Plast Surg 1990;17: 101-12.

20. Borenstein A, Yaffe B, Seidman DS, et al. Tissue expansion in reconstruction of postburn contracture of the first web space of the hand. Ann Plast Surg 1991;26:463-5.

21. Antonyshyn O, Gruss JS, Mackinnon SE, et al. Complications of soft tissue expansion. Br J Plast Surg 1988;41:23950.

22. Lee T, Vaca EE, Ledwon JK, et al. Improving tissue expansion protocols through computational modeling. J Mech Behav Biomed Mater 2018;82:224-34. 